\title{
Modeling and Design of a Controller for a Dehumidifier
}

\author{
Vijaya Saraswathi R J a,1, Sukambika $\mathrm{S}^{\mathrm{b}}$,Wilcy Theresa $\mathrm{F}^{\mathrm{b}}$, Ishwarya $\mathrm{M}^{\mathrm{b}}$, and \\ Srinithi $\mathrm{T}^{\mathrm{b}}$ \\ a Assistant Professor, Dept of EIE, Panimalar Engineering College, chennai \\ ${ }^{b}$ Dept of EIE, Panimalar Engineering College, chennai
}

\begin{abstract}
Many industries like pharmaceutics, plastics, food and confectionery, tobacco and cold storage, maintaining the humidity at the desired level is very important. The aim of this paper is to process the model and to design a controller for a dehumidifier to control the humidity at the desired set point. The air is humidified using a humidity chamber. This humid air which is the primary air is mixed with secondary air from the compressor and sent to the dehumidifier. The dehumidifier used here is a centrifugal separator. The humidity of the dehumidified air is measured using a sensor. The output signal of the sensor is compared to the set point. If the output measured exceeds the set point, accordingly the flow rate of the secondary air to the dehumidifier is varied until it reaches the desired set point . The model of the process is identified from the response of the process to the input signals. The controller is designed for the model obtained and the performance of the controller based on the time domain specification is compared.
\end{abstract}

Keywords. dehumidifier,relative humidity,flow rate,tuning,model parameters

\section{Introduction}

'Modeling and Design of a Controller for a Dehumidifier' is aimed at maintaining the relative humidity at the desired level. Dehumidifiers are used to prevent foul smell and growth of moulds in the basement of buildings in colder countries. They are also used in hot, humid climates to provide an ambient environment. In pharmaceutical industries the humidity must be maintained at the desired point during mixing and weighing of ingredients, punching and packing of tablets etc. to enhance the products' quality and durability. In plastic industries the humidity must be maintained at the proper level to prevent absorption of moisture by the plastic granules and to prevent condensation on the moulds. In cold storages the humidity must be maintained at the desired level to prevent frosting and to prevent fouling. By modeling and designing a controller for a dehumidifier, humidity in the above applications can be controlled in an effective manner.

\footnotetext{
${ }^{1}$ Vijaya Saraswathi R J, Assistant Professor,Dept of EIE,Panimalar Engineering College, Chennai,

E.mail:viji20@yahoo.co.in
} 


\section{Experimental Set Up}

\subsection{Compressor}

The compressor is used to supply pressurized and regulated flow of air. A Rotameter is a tapered glass tube, which has a float that is pushed up or pulled down by flow or gravity. At a higher flow rate more area (between the float and the tube) is needed to accommodate the flow, so the float rises. The float rotates axially as the fluid passes Readings are usually taken from the top of the float.

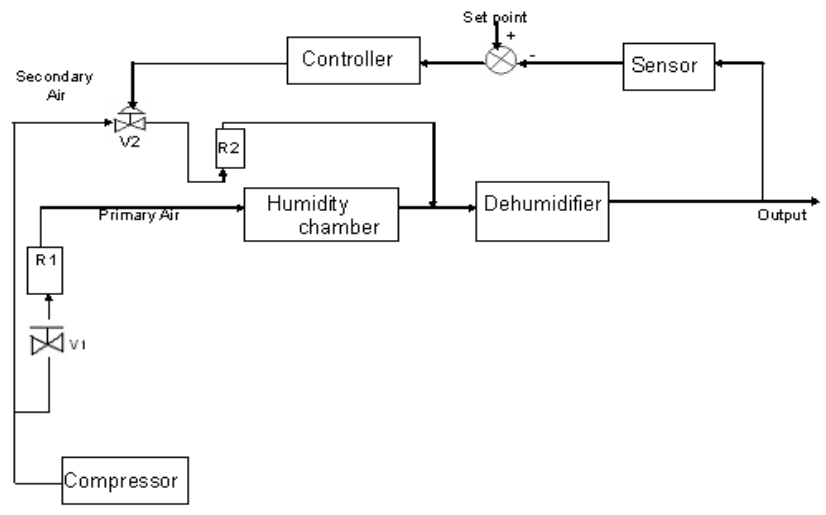

Figure 1. Block Diagram of the Process

\subsection{Humidity chamber}

The humidity chamber is a closed container chamber that is filled with water upto the desired level. Pressurized air from the compressor from after passing through rotameter is made to pass through the chamber, and it forms air bubbles.This humidifies the air.

\subsection{Power supply}

Power supply of range (0-5) V is given for the working of the sensor.

\subsection{Sensor}

HIH-3610 is a sensor which measures relative humidity and its output is in volts. The voltage is then converted into corresponding relative humidity by using the formula.

$$
\mathrm{RH}=(\text { Voltage }-0.95) / 0.03032
$$

\subsection{Dehumidifier}

The primary air from the compressor is humidified in a humidity chamber. The humidity chamber consists of a chamber of water. When air is bubbled through it, it 
gets humidified. Dehumidification[6] is done using centrifugal separator. In the centrifugal separator the humid air is sent tangentially to the walls of the container. The humid air goes in a circular path and the water due to its high density comes down and the dehumidified air rises up

\subsection{Explanation of the Process}

The primary air from the compressor whose flow rate is measured using the rotameter $\mathrm{R} 1$ is sent to the humidity chamber in which the air is humidified. This humidified air

is then mixed with the secondary air whose flow rate is measured using the rotameter $\mathrm{R} 2$. This mixture is then sent to the dehumidifier for dehumidification process[4]. The dehumidifier employed here is a centrifugal separator. Here due to the centrifugal action, air and water gets separated, thus lowering the humidity[5]. The humidity of the dehumidified air from the centrifugal separator is measured using a HIH-3610 sensor.The comparison is made between the actual setpoint and measured output signal from the sensor. If the humidity measured by the sensor varies from the desired set point, then the flow rate of the secondary air to the dehumidifier is varied by the controller until it reaches the desired set point.

\section{Practical Values Observed}

The relative humidity of the air from the dehumidifier is measured for different flow rates of secondary air until the value reaches the steady state.

\subsection{Flow Rate vs Relative Humidity}

It is found that when the flow rate of the secondary air increases, the outlet humidity of the dehumidifier decreases. So the controller is designed in such a way that the desired humidity level is maintained[7].

\section{Process Identification}

From the experimental data collected, the dynamical nature of this process is identified and from the results the process model is obtained to design a control system[6]. Process identification is done from the dynamical nature of the process. The dynamics of the process can be identified from the response of the process to pulse, step, ramp or other deterministic input signals. Here, a step input is applied to the process and the resulting data from the process is examined to deduce the required information. A plot of the output response of a process to a step change in input is referred to as a process reaction curve. The process is identified as first order plus dead time model and the model parameters can be identified from the inspection of the process reaction curve.[8].

The model parameters like $\mathrm{k}_{\mathrm{m}}$ (static gain), $\tau$ (time constant), $\theta$ (time delay) are determined by the following methods.

1. Graphical Approach.

2. Two-Point Method[8]

3. Sundaresan Krishnaswamy (SK)Method. 
4.1. Relative Humidity vs Time for the flow rate of $0 \mathrm{lpm}$

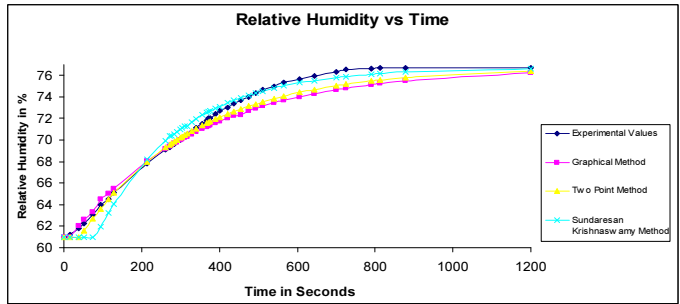

Figure 2. Relative humidity Vs Time(0 lpm)

Here, the SK method is found to have a least error when compared to the experimental values.

\subsection{Relative Humidity vs Time for the flow rate of 0.}

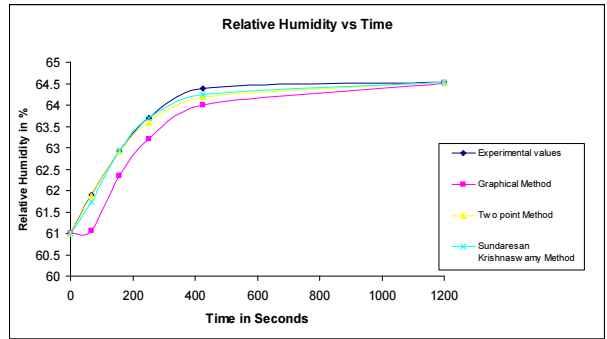

Figure 3. Relative humidity Vs Time(0.1 lpm)

Here, the SK method is found to have a least error when compared to the experimental values[9].

4.3. Relative Humidity vs Time for the flow rate of $0.2 \mathrm{lpm}$

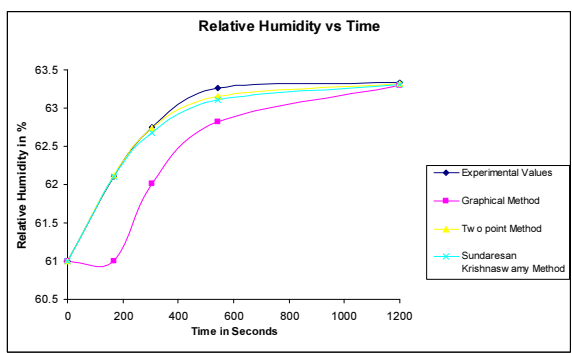

Figure 4. Relative humidity Vs Time(0.2 lpm)

Here, the Two Point method is found to have a least error when compared to the experimental values.

\section{Controller Tuning}

The controller is designed for the model obtained using the following methods.[2] 
1. $\quad$ PID tuning (Ziegler-Nichols method)[3]

2. Direct Synthesis Method[1]

Table 1. Tabulation of Ziegler-Nichols

\begin{tabular}{|l|l|l|l|l|}
\hline Type of Control & $\mathrm{Gc}(\mathrm{s})$ & $\mathrm{Kc}$ & $\tau_{\mathrm{i}}$ & $\tau_{\mathrm{d}}$ \\
\hline Proportional(P) & $\mathrm{Kc}$ & $0.5 \mathrm{Ku}$ & & \\
\hline Proportional-Integral(PI) & $\mathrm{Kc}\left(1+1 / \tau_{\mathrm{i}} \mathrm{S}\right)$ & $0.45 \mathrm{Ku}$ & $\mathrm{Pu} / 1.2$ & \\
\hline $\begin{array}{l}\text { Proportional-Integral- } \\
\text { Derivative(PID) }\end{array}$ & $\mathrm{Kc}\left(1+\tau_{\mathrm{d}}+1 / \tau_{\mathrm{i}} \mathrm{S}\right)$ & $0.6 \mathrm{Ku}$ & $\mathrm{Pu} / 2$ & $\mathrm{Pu} / 8$ \\
\hline
\end{tabular}

Table 2. Tabulation Comparing the two Methods

\begin{tabular}{|l||l|l|l|l|}
\hline Methods & $\begin{array}{l}\text { Rise } \\
\text { Time(secs) }\end{array}$ & Overshoot & $\begin{array}{l}\text { Response } \\
\text { Time(secs) }\end{array}$ & $\begin{array}{l}\text { Peak } \\
\text { Time(secs) }\end{array}$ \\
\hline $\begin{array}{l}\text { Direct } \\
\text { Synthesis }\end{array}$ & 96 & 0 & 120 & 0 \\
\hline $\begin{array}{l}\text { Ziegler- } \\
\text { Nichols }\end{array}$ & 53.75 & 1.4 & 276.1 & 98.4 \\
\hline
\end{tabular}

\section{Conclusion}

The model of the process is identified using two methods for various flow rates. From the comparisons made, it is found that S K method has the least error and has the nearest value to the experimental data when compared to the other method.From the comparison made for different tuning methods, it is found that the Direct Synthesis Method has a comparatively lower response time and zero overshoot. So the Direct Synthesis Method is found to be the best suited method.

\section{References}

[1] Getting in tune with Ziegler-Nichols. Thomas R. Kurfess, PhD, in the Academic Viewpoint column, Control Engineering magazine, Feb 2007 issue, p. 28,

[2] Y. Ma, Y. Liu and C. Wang Elissa. Design ofParameters Self-tuning Fuzzy PID Control for DCMotor . in FroG. of Second International Conference on Industrial Mechatronics and Automation ICIMA, vol. 2, p. 345-348, 2010.

[3] K. A. Naik and P. Shrikant. Stability Enhancement of DC Motor using IMC Tuned PID Controller IJAEST International Journals of Advanced Engg. Science and Technologies, 2011System Analysis and Control. Mc Graw Hills book company, New York. vol. 4, Issue No. I, p. 092- 096,

[4] George Stephnopoulous. Chemical process control .Prentice Hall of India Pvt. Ltd. New Delhi, 2001.

[5] Donald R. Coughanowr, Steven E. LeBlanc .Process Systems Analysis and Control .Third Edition

[6] M. Bloomstine, O. Sorensen, and J. Thomsen .Main cable corrosion by dehumidification. IABSE Conference Report, Conference on Operation, Maintenance and Rehabilitation of Large Infrastructure Projects, Copenhagen, Denmark 2006.

[7] Y. S. Sharma, gec dahod; D. B. Jani, gec dahod; Milan Pithva, gec dahod; M. R. Chandravadia, gec dahod; Rushik Thummar, gec dahod. A Review of Desiccant Dehumidification Assisted AirConditioning System. Jan 2019

[8] Muthuraj, B., Mahesh, V., Senthil, A hybrid petri net approach for polyethylene terephthalate bottle manufacturing system. Journal of Computational and Theoretical Nanoscience. 2016.

[9] Muthuraj, B., Mahesh, V., Senthil, R. Simulation of three tank system using hybrid perti net for batch process.International Journal of Applied Engineering Research.2016. 